\title{
Optimization of work performance of snow removal work trains on the basis of linear programming
}

\author{
Aleksey Manakov ${ }^{1, *}$, Andrey Abramov ${ }^{1}$, Andrey Ilinykh ${ }^{1}$, Vladimir Aksenov ${ }^{2}$ \\ ${ }^{1}$ Siberian Transport University, Dusi Kovalchuk st., 630049, Novosibirsk, Russia \\ ${ }^{2}$ Russian University of Transport, Obrazcova Str., 9b9, 127994, Moscow
}

\begin{abstract}
The introduction of monitoring systems for the work performance of special rolling stock and monitoring the load of snow removal work trains revealed a number of shortcomings in the planning, organization, and recording of work performed by snow removal work trains. The elimination of the identified problems is possible on the basis of optimization of work performance, the implementation of which can be achieved on the basis of existing systems with appropriate additional functionality. For this purpose, in the framework of the theoretical studies presented in the paper, a methodology for optimization of work performance of snow removal work trains has been developed. Linear programming is adopted as a method of solving the optimization problem. On the basis of the algorithm for solving the transport problem, the problem of minimizing the cost of snow removal from various sections of the track by the existing park of work trains is formulated, for which a mathematical model is constructed that includes the objective function and the corresponding restrictions. The results of the study show that the widespread use of work planning on the basis of the presented optimization methodology will make it possible to make the most efficient use of snow removal equipment and, as a result, to reduce the cost of this type of railway track maintenance work.
\end{abstract}

\section{Introduction}

The strategy for the development of the railway industry involves the development of fundamentally new systems for diagnosing and monitoring of infrastructure and rolling stock that use algorithms of artificial intelligence in their work.

One of such systems was developed at the center "Automated systems for diagnostics and monitoring of rolling stock and tracks" of JSC "VNIIZhT" (Railway Research Institute). The automated system for monitoring the work performance of a special rolling stock (AS MWPSRS) is designed to monitor and record the technological characteristics of work trains with the ability to transfer information to an automated control system for the operation and maintenance of special rolling stock using signals from the GLONASS/GPS

\footnotetext{
${ }^{*}$ Corresponding author: asi@stu.ru
} 
satellite navigation system and GSM/GPRS data channels [1, 2]. Currently, this system is being implemented and is being tested.

With the purpose of expanding the functional of the AS MWPSRS, a monitoring system for loading snow removal work trains SRWT-2 [3] was developed and implemented at the Siberian State Transport University. The monitoring system for loading snow removal work trains contains four ultrasonic sensors installed above the conveyor belt, which continuously measure the height and speed of the snow mass and automatically transfer them to cubic meters. In addition, the system records the place and time of start of operation, the operating time of the conveyor belt per shift, how many times unloading was made, and the temperature of the surrounding air at the time of snow removal.

Operation testing of the system showed the existing shortcomings in planning, organizing, and recording the work performed by snow removal work trains. We can mention the main ones:

1. The discrepancy between the volumes of actually loaded snow in gondola cars and the record of work registered in the logbook by the number of unloads.

2. Substantial light loading of work trains while following to unload.

3. Long duration of "hot" downtime.

The noted problems indicate inefficient use of available resources and indicate the need to optimize the work performance of snow removal work trains [4]. Moreover, the existing capabilities of these systems make it possible to use them not only for registering all possible parameters of the operation of work trains, but also as an optimization tool, by adding the appropriate functional in them. Thus, the current main task is to develop a methodology for optimizing the work performance of snow removal work trains. The main goal of optimization, which is set for the employees of the track complex, is a reduction of operating costs of up to $30 \%$, as well as an increase in productivity due to the intensification of snow removal works.

\section{Methods of research}

Today, a large number of methods are available for solving optimization problems: the use of indefinite Lagrange multipliers, calculus of variations, dynamic programming, etc. The choice of optimization method cannot be considered apart from the main operation task and should be based on knowledge of the possibilities of existing optimization methods and on features of the technology under consideration. Analysis of existing optimization methods allowed us to focus on linear programming as the most suitable for estimating the work performance of snow removal work trains. This choice is caused by a number of positive moments, which consist in the popularity and efficiency of this method and its algorithmic nature, which makes it possible to exclude manual calculations and completely automate (program) them. In addition, this optimization method is implemented and widely used in various software products.

There are typical optimization problems solved by the linear programming method, such as: "The task of resource allocation", "The task of determining the optimal assortment", "The task of the balance of the plan", "The task of purpose", etc. Algorithms for solving these problems are known and confirmed their efficiency in solving real operation problems $[5]$.

Unfortunately, the use of existing methods to optimize the process of snow removal on the railway is difficult due to the specifics of the operation and a large number of restrictions that often change over time. In fact, the closest task to the work performance of snow removal work trains is the "Transport task", which was taken as a basis for the development of the optimization algorithm. 
In general, the formulation of the transport task consists in determining the optimal transportation plan for some cargo $m$ from the departure points $A_{1}, A_{2}, \ldots, A_{m}$, to $n$ destination points $\mathrm{B}_{1}, \mathrm{~B}_{2}, \ldots, \mathrm{B}_{\mathrm{n}}$. In this case, the minimum cost of transportation of the whole cargo or the minimum time for its delivery is usually taken as a criterion of optimality. In an explicit form, this task cannot be applied and requires adaptation to the operating process of snow removal.

\section{Statement of the problem}

An important role in the rationality of the optimal solution is played by the statement of the problem that determines the objective function and the establishment of appropriate restrictions. With regard to the work of snow removal work trains, the optimization problem can be formulated in two main variants:

1. Minimizing costs for snow removal. Such a statement of the problem is typical for the planned work of snow removal equipment, when the existing snow cover on the sections of the railway track does not interfere with the operation of the rolling stock and road infrastructure. This work is typical for most of the winter period.

2. Maximum rapid removal of snow on the track section. This task occurs during the period of intense precipitation, when their volume can negatively affect the efficiency and safety of the transportation process.

Let us consider the problem in a general form. The minimization of costs for snow removal is taken as its criterion of optimality.

At $\mathrm{m}$ stations (sections of the track), it is necessary to remove snow with the volume a1, $\mathrm{a} 2, \ldots$, am $\mathrm{m} 3$, respectively. This snow can be removed and taken out by the $\mathrm{n}$ number of snow removal work trains, whose capacity is b1, b2, .., bn $\mathrm{m} 3$, respectively. All snow removal work trains are located in different places at different distances from the site of operation. The prime cost of removal of $1 \mathrm{~m} 3$ of snow cij (thousand rubles) by snow removal work trains from different sections of the track is determined by the matrix shown in Table. 1. It is necessary to draw up a plan for the removal of snow from the stations (sections of the track), at which the total cost of work performance would be minimal.

Table 1. Matrix of the prime cost of removal of $1 \mathrm{~m}^{3}$ of snow.

\begin{tabular}{|c|c|c|c|c|}
\hline \multirow{2}{*}{$\begin{array}{c}\text { Snow removal } \\
\text { work train }\end{array}$} & \multicolumn{4}{|c|}{ The cost of work performance on the section of the track (station) } \\
\cline { 2 - 5 } & 1 & 2 & $\ldots . .$. & $\mathrm{c}_{\mathrm{i} 1}$ \\
\hline SRWT $_{1}$ & $\mathrm{c}_{11}$ & $\mathrm{c}_{21}$ & $\mathrm{c}_{\mathrm{i} 2}$ & $\mathrm{c}_{\mathrm{m} 1}$ \\
\hline SRWT $_{2}$ & $\mathrm{c}_{12}$ & $\mathrm{c}_{22}$ & $\ldots$ & $\ldots$ \\
\hline$\ldots$ & $\ldots$ & $\ldots$ & $\mathrm{c}_{\mathrm{m} 2}$ & $\ldots$ \\
\hline SRWT $_{\mathrm{j}}$ & $\mathrm{c}_{1 \mathrm{j}}$ & $\mathrm{c}_{2 \mathrm{j}}$ & $\ldots$ & $\ldots$ \\
\hline$\ldots$ & $\ldots$ & $\ldots$ & $\mathrm{c}_{\mathrm{mj}}$ & $\mathrm{c}_{\mathrm{mn}}$ \\
\hline SRWT $_{\mathrm{n}}$ & $\mathrm{c}_{1 \mathrm{n}}$ & $\mathrm{c}_{2 \mathrm{n}}$ & $\ldots$ \\
\hline
\end{tabular}

\section{Solution}

Let's denote the variables:

xij - the amount of snow removed and taken out from the i-th section of the track (station) by $\mathrm{j}$-th snow removal work train $(\mathrm{i}=1,2, \ldots, \mathrm{n} ; \mathrm{j}=1,2, \ldots, \mathrm{m})$.

cij - the cost of removal and taking out of $1 \mathrm{~m} 3$ of snow from the i-th section of the track (station) by $\mathrm{j}$-th snow removal work train $(\mathrm{i}=1,2, \ldots, \mathrm{n} ; \mathrm{j}=1,2, \ldots, \mathrm{m})$.

ai - the volume of snow that must be removed from the $i$-th section of the path (station) $(\mathrm{i}=1,2, \ldots, \mathrm{m})$. 
$\mathrm{bj}$ - the volume of snow that can be taken by the $\mathrm{j}$-th snow removal work train at a time $(j=1,2, \ldots, n)$.

The cost of removal and taking out of $1 \mathrm{~m} 3$ of snow cij will be different in all cases under consideration, because, in addition to the basic costs, it depends on the remoteness of the work train from the place of work performance and the estimated amount of snow removal. In general form, cij is determined by the formula:

$$
c_{i j}=\frac{c_{i j}^{n}+c_{i j}^{y}+c_{i j}^{6}}{x_{i j}},
$$

where $c_{i j}^{n}$ - the cost of transporting the snow removal work train from its location to the place of work performance, rubles; $c_{i j}^{y}$ - cost of work of the snow removal work train for snow removal, rub .; $c_{i j}^{B}$ - the cost of transporting a loaded snow removal work train to the place of unloading, rubles.

Let's compose the mathematical model of the problem.

The model of the problem under consideration is open, since the amount of snow that must be removed from the section of the track is not likely to correspond to the total volume of maximum load of snow removal work train, i.e.:

$$
\sum_{i=1}^{m} a_{i} \neq \sum_{j=1}^{n} b_{j} .
$$

To solve the task, it is necessary and sufficient that the total volume of snow that must be removed is equal to the possibilities of snow removal work trains, i.e. reduce the problem to a closed type:

$$
\sum_{i=1}^{m} a_{i}=\sum_{j=1}^{n} b_{j} .
$$

For this, if the volume of snow exceeds the capacity of the work trains (the most possible situation), i.e. with inequality:

$$
\sum_{i=1}^{m} a_{i}>\sum_{j=1}^{n} b_{j},
$$

it is necessary to introduce a fictitious $(i+1)$-th snow removal work train with the possibility of loading:

$$
b_{n+1}=\sum_{i=1}^{m} a_{i}-\sum_{j=1}^{n} b_{j},
$$

and the corresponding prime cost is considered equal to zero: $c_{i n+1}=0(i=1, \ldots, m)$, because in fact, this amount of snow will remain untouched.

If the total amount of snow is not enough to fully load all the work trains (less likely situation), i.e.: 


$$
\sum_{i=1}^{m} a_{i}<\sum_{j=1}^{n} b_{j},
$$

then, in contrast to the classical transport problem, in our case, one of the work trains must be removed from the program for planning. The criterion by which an unnecessary work train is selected is the maximum total prime cost of removal of $1 \mathrm{~m}^{3}$ of snow over all sections of the track:

$$
\sum_{i=1}^{m} c_{i j} \rightarrow \max .
$$

This reduces the problem to a problem with a closed model, and the condition for removal of the necessary amount of snow is provided by fulfilling the following conditions:

$$
\begin{gathered}
\sum_{i=1}^{m} x_{i j}=b_{j}(j=1, \ldots, n), \\
\sum_{j=1}^{n} x_{i j}=a_{i}(i=1, \ldots, m), \\
x_{i j} \geq 0(i=1, \ldots, m ; j=1, \ldots, n) .
\end{gathered}
$$

The total cost removal of snow will be:

$$
F=\sum_{i=1}^{n} \sum_{j=1}^{m} c_{i j} x_{i j},
$$

Thus, the mathematical statement of this problem consists in finding such a nonnegative solution of the system of linear equations (8) and (9), for which the objective function (11) takes a minimum value.

\section{Example}

Let's consider the possibility of implementing the presented methodology in the following example.

At three stations №1, №2 and №3, it is necessary to remove snow from the sections of the track, the characteristics of which are given in Table. 2. There are 4 snow removal work trains for performance of these works, the characteristics and remoteness of which are presented in Table. 3. It is necessary to draw up a plan for snow removal from the stations, in which the total cost of work performance would be minimal.

Table 2. Characteristics of track sections.

\begin{tabular}{|c|c|c|c|}
\hline Station & $\begin{array}{c}\text { Total length of the } \\
\text { section, } \mathrm{km}\end{array}$ & $\begin{array}{c}\text { Average snow cover } \\
\text { on the section, } \mathrm{mm}\end{array}$ & $\begin{array}{c}\text { Estimated snow volume at } \\
\text { the section, } a_{i}, \mathrm{~m}^{3}\end{array}$ \\
\hline №1 & 2,23 & 150 & 669 \\
\hline №2 & 0,358 & 250 & 179 \\
\hline №3 & 1,54 & 200 & 616 \\
\hline
\end{tabular}


Table 3. Characteristics of snow removal work trains.

\begin{tabular}{|c|c|c|c|c|}
\hline \multirow{2}{*}{$\begin{array}{c}\text { Snow removal work } \\
\text { train }\end{array}$} & \multirow{2}{*}{$\begin{array}{c}\text { Maximum volume of } \\
\text { load, } b_{i}, \mathrm{~m}^{3}\end{array}$} & \multicolumn{3}{|c|}{$\begin{array}{c}\text { Remoteness from the place of work } \\
\text { performance, } \mathrm{km}\end{array}$} \\
\cline { 3 - 5 } & 160 & No1 & No 2 & No 3 \\
\hline SRWT № 1 & 285 & 21 & 14 & 29 \\
\hline SRWT № 2 & 160 & 73 & 41 & 24 \\
\hline SRWT № 3 & 410 & 69 & 106 & 120 \\
\hline SRWT № 4 & 75 & 38 & 29 \\
\hline
\end{tabular}

Firstly, we determine the prime cost of removal of $1 \mathrm{~m}^{3}$ of snow by different trains from different stations using formula (1). The results of the calculations are shown in Table. 4.

The model of the problem under consideration is not closed, since

$$
\sum_{i=1}^{3} a_{i} \neq \sum_{j=1}^{4} b_{j} \rightarrow(669+179+616) \neq(160+285+160+410) .
$$

The amount of snow that needs to be removed from the stations is $449 \mathrm{~m}^{3}$ higher than the total capacity of the snow removal work trains, and, based on conditions (4) and (5), we add one more dummy snow removal work train SRWT +1 . Thus, the total initial data for the calculation are given in Table. 4.

Table 4. Initial data for the calculation.

\begin{tabular}{|c|c|c|c|c|c|c|}
\hline \multirow{2}{*}{ Station } & \multicolumn{5}{|c|}{$\begin{array}{l}\text { The prime cost of removal of } 1 \mathrm{~m}^{3} \text { of snow by a SRWT } \\
\text { from a station, } c_{\mathrm{ij}} \text {, thousand rubles }\end{array}$} & \multirow{2}{*}{$\begin{array}{l}\text { Volume of } \\
\text { snow on the } \\
\text { section, ai, m }\end{array}$} \\
\hline & $\begin{array}{l}\text { SRWT } \\
\text { No } 1 \\
\end{array}$ & $\begin{array}{l}\text { SRWT } \\
\text { No } 2 \\
\end{array}$ & $\begin{array}{l}\text { SRWT } \\
\text { No } 3\end{array}$ & $\begin{array}{l}\text { SRWT } \\
\text { No } 4\end{array}$ & $\begin{array}{c}\text { SRWT } \\
+1\end{array}$ & \\
\hline No 1 & 1,282 & 3,947 & 3,742 & 4,052 & 0 & 669 \\
\hline No 2 & 2,806 & 7,977 & 20,427 & 7,403 & 0 & 179 \\
\hline No 3 & 1,769 & 1,491 & 6,834 & 1,769 & 0 & 616 \\
\hline $\begin{array}{c}\text { Volume of } \\
\text { loading, } b_{\mathrm{i}}, \mathrm{m}^{3}\end{array}$ & 160 & 285 & 160 & 410 & 449 & \\
\hline
\end{tabular}

The systems (8) and (9), taking into account the initial data, can be written as follows:

$$
\begin{gathered}
\left\{\begin{array}{l}
x_{11}+x_{21}+x_{31}=160 \\
x_{12}+x_{22}+x_{32}=285 \\
x_{13}+x_{23}+x_{33}=160 \\
x_{14}+x_{24}+x_{34}=410 \\
x_{15}+x_{25}+x_{35}=449
\end{array}\right. \\
\left\{\begin{array}{l}
x_{11}+x_{12}+x_{13}+x_{14}+x_{15}=669 \\
x_{21}+x_{22}+x_{23}+x_{24}+x_{25}=179 \\
x_{31}+x_{32}+x_{33}+x_{34}+x_{35}=616
\end{array}\right.
\end{gathered}
$$

In accordance with (11), the objective function $F$ has the form:

$$
\begin{gathered}
F=1,282 x_{11}+3,947 x_{21}+3,742 x_{31}+4,052 x_{41}+0 x_{51}+2,806 x_{12}+7,977 x_{22}+20,427 x_{32}+7,403 x_{42}+0 x_{52}+ \\
+1,769 x_{13}+1,491 x_{23}+6,834 x_{33}+1,769 x_{43}+0 x_{53} \rightarrow \min
\end{gathered}
$$


To calculate by the presented initial data and the generated mathematical model, we use the tool "Find solutions" of MS Excel. The results of the calculation are presented in Table. 5 .

Table 5. Results of calculation in MS Excel using the tool "Find Solution".

\begin{tabular}{|c|c|c|c|c|c|c|c|}
\hline Station & SRWT1 & SRWT2 & SRWT3 & SRWT4 & SRWT+1 & $\begin{array}{c}\text { Actual, } \\
\text { total } \\
\text { volume } \\
\text { of snow } \\
\text { removal } \\
\text { from the } \\
\text { station }\end{array}$ & $\begin{array}{c}\text { Total } \\
\text { volume } \\
\text { of snow } \\
\text { at the } \\
\text { station, } \\
\mathrm{m}^{3}\end{array}$ \\
\hline No 1 & 160 & 0 & 160 & 79 & 270 & 399 & 669 \\
\hline No 2 & 0 & 0 & 0 & 0 & 179 & 0 & 179 \\
\hline No 3 & 0 & 285 & 0 & 331 & 0 & 616 & 616 \\
\hline $\begin{array}{l}\text { Actual volume of } \\
\text { loading of the work } \\
\text { train, } \text { m }^{3}\end{array}$ & 160 & 285 & 160 & 410 & 449 & & \\
\hline $\begin{array}{l}\text { Maximum possible } \\
\text { loading of the work } \\
\text { train, } \text { m }^{3}\end{array}$ & 160 & 285 & 160 & 410 & 449 & & \\
\hline $\begin{array}{l}\text { Total costs for } \\
\text { snow removal, } \\
\text { thousand rubles. }\end{array}$ & 2134 & & & & & \\
\hline
\end{tabular}

As a result of the solution of the problem under the set conditions, it was obtained that the minimum costs for snow removal at 3 stations could be 2134 thousand rubles. At the same time, it is necessary that the snow removal work trains SRWT1 and SRWT3 are worked only at station №1, SRWT2 only at station V 3, and SRWT4, having loaded snow in the volume of $331 \mathrm{~m}^{3}$ at station №3, continued work at station №1. As a result, we can see that all snow removal work trains are fully loaded. Station №1 in the volume of $270 \mathrm{~m}^{3}$ and station №2 in the volume of $179 \mathrm{~m}^{3}$ were not completely cleaned up. This amount of work is carried forward to the next planning period, taking into account the changed location of the work trains.

\section{Conclusions}

Based on the theoretical studies, the methodology for optimizing the work performance of snow removal work trains was proposed. This methodology is based on linear programming and allows taking into account the following main characteristics of the operating process that determine the total cost of snow removal:

1. Remoteness of work trains from the place of work performance.

2. Remoteness from the place of work performance to the place where the snow is unloaded.

3. Scope of work (taking into account the height of the snow cover and the length of the track section).

4. Completeness of loading of the snow removal work train.

5. Necessary number of snow removal work trains to perform work.

This methodology excludes not all the negative factors of the organization and planning of work noted above. In the capacity of its development in the future, the following problems can be solved:

1. Reduction of "hot" downtime of snow removal work trains.

2. Accounting the technology for the work performance of snow removal work trains of various types and the choice of the most optimal for a particular section of the track. 
3. On the basis of technical and technological capabilities of snow removal work trains, produce technological justification for snow removal by a complex of work trains within boundaries of the station.

Depending on the weather and operation conditions, it is possible to plan the work according to the described algorithm both for the nearest period (shift, day) and for a longer term (week, month).

The common use of work planning on the basis of the presented optimization methodology will make it possible to use snow removal equipment as efficiently as possible and, as a consequence, to reduce the costs of this type of work for the maintenance of the railway track.

\section{References}

1. V. Gorelkin, "Duomatiki” and "Unimaty" are taken under control (Gudok, 2016)

2. Description of the AS MOSRS, https://sps.gis.ru.net/article/opisanie-as-krsps

3. A. Matveev, The snow will be measured by sound (Gudok, 2017)

4. A.L. Manakov, S.A. Kolarzh, G.G. Yadroshnikova, Materials of the VIII International Scientific and Technical Conference "Polytransport Systems",SSTU, 550-554 (2015)

5. B. Bundy, Fundamentals of linear programming. Translation from English (Radio and Communication, Moscow, 1989) 